J. Neurol. Neurosurg. Psychiat., 1958, 21, 297.

\title{
THE EFFECT OF RESERPINE ON THE DURATION OF MANIC ATTACKS
}

\author{
BY \\ DAVID C. WATT \\ From St. John's Hospital, Stone, Bucks.
}

Many authors, in advocating special treatments for mania, do not consider the duration of the illness but give instead the number or percentage of those recovered, improved, or unchanged. Smith, Hastings, and Hughes (1943), Ziskind, SomerfeldZiskind, and Ziskind (1945), and Schiele and Schneider (1949) advocate E.C.T. General experience with this treatment is that it must often be given intensively and relapses are frequent (Noyes, 1953; Mayer-Gross, Slater, and Roth, 1954; Sargent and Slater, 1948). Hennelly (1936), Kearney and Courtney (1938), and Wilson and Gillman (1938) recommend prolonged narcosis. Lithium is recommended by Cade (1949), Schou, Juel-Nielsen, Strömgren, and Voldby (1954), Glesinger (1954), and Rice (1956), chlorpromazine by Vaughan, Lieberman, and Cook (1955), and Kinross-Wright (1955). With each of these treatments about half the cases remitted during the period of treatment. As most attacks of mania are self-limiting, however, such results do not demonstrate the treatment's efficacy.

The beneficial effect of reserpine on excited patients has been noted by several authors (Barsa and Kline, 1955; Sommerness, Lucero, Hamlon, Erickson, and Matthews, 1955; Altschule, 1956; Hes and Bracha, 1956). Its calming effect in mania, the illness most frequently characterized by excitement, is mentioned specifically by Colombati and Benassi (1954), Flach (1955), Glynn (1955), Kirkpatrick and Saunders (1955), Kinross-Wright (1955), Luttrell and Morrison (1955), Brooks (1956), Sarwer-Foner and Ogle (1956), and Zeller, Graffagnino, Cullen, and Rietman (1956). No author has yet measured its effect on the duration of manic attacks. The efficacy of particular treatments in mania cannot be estimated by the proportion of attacks issuing in " recovery" or " improvement," however. The majority terminate without special treatment and it is imperative, therefore, to take into account the duration of the attack which is, at present, the only measurable index of the treatment's effect. This is undertaken in the present study to make a more precise assess- ment of reserpine in the treatment of mania and to compare it with other treatments.

\section{Case Material and Method}

For this investigation two groups of manic attacks occurring in female patients are compared. The first group (Group 1) consisted of 19 attacks occurring in 18 patients, whose average age was 43.7 years with a range of 17 to 68 years (S.D. $=11.5$ ); the patients comprised all the female cases diagnosed as suffering from mania and admitted to a county mental hospital (St. John's Hospital, Stone, Bucks.) between December 3, 1955, and February 6, 1957. The only specific treatment given during the attacks included in Group 1 was the administration of reserpine. The initial dose varied from $8 \mathrm{mg}$. to $15 \mathrm{mg}$. daily; $8 \mathrm{mg}$. was the most frequent initial dose and it was usually given intramuscularly. This was replaced by oral administration within a few days and the dose reduced as the patient improved. Once the dose was increased to $20 \mathrm{mg}$. daily for a few days. Two cases improved shortly after admission and received no specific treatment. The duration of treatment ranged from two to 10 weeks. The most frequent period of treatment was six to seven weeks.

The second group (Group 2) consisted of 44 attacks of mania in 32 patients whose average age was 46.6 years with a range of 20 to 72 years (S.D. $=16 \cdot 1)$. These were all the female patients suffering from mania discharged from St. John's Hospital during the five years 1951-55. Three attacks included in Group 1 occurred in patients who had had earlier attacks of mania for which they were admitted to other hospitals than St. John's. These earlier attacks occurred in the period 1951-52 and are included in Group 2. The attacks in Group 2 were treated by various methods: prolonged narcosis (four attacks); E.C.T. (nine attacks); insulin coma therapy (three attacks); chlorpromazine (two attacks). The majority had no specific treatment ( 26 attacks).

Mania (and hypomania) is possibly the most protean of the major psychiatric syndromes and the diagnosis is correspondingly difficult (Deron, 1928). The features commonly relied on are increased motor activity, increased talk, rapid thought with facility of association, distractibility, euphoric or grandiose mood, often labile and tending to anger. In distinction from schizophrenia, thought content and mood are usually consonant; delusions do occur, but are usually unsystematized and are less common than distortions arising from features 
of the patient's circumstances and environment which he finds displeasing. A setting of clear consciousness is present except in severe cases where delirium may occur and hallucinations be present (Lewis, 1956; Mayer-Gross et al., 1954). The cases selected here conformed to this general picture. The majority were seen by the author during the attack and all the case records were examined by him. One patient who was of low average intelligence (I.Q. 84) suffered from petit mal. In no other case was any complicating factor known to be present. Previous or subsequent attacks of affective illness, necessitating the patient's admission to hospital and resulting in discharge, occurred in 41 of the 50 patients. In six attacks (one in Group 1, five in Group 2), there was a depressive spell, three at the beginning, two at the end, and one interpolated in the attack. The longest of these did not exceed one month and they are included in the duration of the attack.

The duration of hospital stay in each attack was estimated in both groups which were then compared in this respect. The duration of hospital stay was taken as the period between the date of admission to hospital and the date of leaving. Three cases were exceptional: in Group 1 a patient was treated with chlorpromazine and relapsed. She was then treated with reserpine and the duration of the attack of mania is dated from the start of this treatment. In Group 2 one patient was admitted for six weeks to a general hospital for the treatment of diabetes. She was mentally ill throughout this time, and, proving unmanageable, was returned to the mental hospital. The duration of the manic attack was here calculated from the date of first admission to the mental hospital to the date of her discharge home and includes the period spent in the general hospital. A second patient discharged herself while still unwell and was admitted as a certified patient 21 days later. The duration of hospital stay was here calculated from the date of the first admission until the date of the second discharge. It would have been most satisfactory to compare both groups in respect of the total duration of the attack, but this was not possible as the dates of admission and discharge from hospital are the only temporal features of the attack which are certain in every case.

The time between the onset of an attack and the patient's discharge from hospital can be divided into three periods: first, that between the onset of the attack and admission to hospital; second, that between admission to hospital and recovery from the attack; third, that between recovery and discharge from hospital. The duration of the attack differs from the duration of hospital stay in respect of the first and third of these periods whose mean duration is therefore compared in the two groups of manic attacks. The estimation of the first period is less satisfactory than of the third, however, as the date of onset of an attack was seldom clearly stated in the clinical notes. This is understandable as it was not of immediate practical importance to the receiving doctor who, in addition, depended upon the retrospection of the patient or of a witness. It is given as an answer to one of the questions in the statement of particulars of both voluntary and certified patients, and it is from this source that it has been obtained by the author in the majority of cases. Recovery, on the other hand, took place in hospital and was of such immediate consequence, e.g., in determining the date of discharge, that it was noted in all but eight attacks (one in Group 1, seven in Group 2). In five attacks the patients discharged themselves before recovery took place, and in three the notes were incomplete.

\section{Results}

The mean duration of hospital stay in the group treated with reserpine is 11.0 weeks (range 3-22, S.D. = 11.3) and in the group in which this treatment was not used 19.0 weeks (range 3-50, S.D. = 11.4) and this difference is significant $(t=2 \cdot 90$, $\mathrm{P}<0.01$, d.f. $=61$ ).

The date of onset was determined in 17 out of 19 attacks in Group 1, and in 34 out of 44 attacks in Group 2, and the period between this date and hospital admission was calculated in each case. The mean period between onset and date of admission is 3.2 weeks for Group 1 (range 1-13, S.D. = 3.2) and $2 \cdot 2$ weeks for Group 2 (range 1-12, S.D. $=2 \cdot 3$ ).

The period between recovery and date of discharge was calculated for 18 out of 19 attacks in Group 1 and for 37 out of 44 attacks in Group 2. The mean is 4.9 weeks for Group 1 (range 1-13, S.D. = 3.5) and $4 \cdot 5$ weeks for Group 2 (range 1-19, S.D. = 4.1).

A second opportunity of comparing attacks of mania treated with reserpine with those otherwise treated presented itself in eight patients whose illness was recurrent. Each of these patients had one attack treated with reserpine in St. John's Hospital, while previous attacks (a few of which had been spent in other mental hospitals) had not been treated with reserpine. Table I shows, for each of the eight

TABLE I

DURATION OF ATTACKS OF MANIA TREATED WITH RESERPINE AND BY OTHER METHODS IN PATIENTS

\begin{tabular}{c|c|c}
\hline Patient & Dates of Admission & Duration of Hospital Stay (weeks) \\
\hline 1 & 9.7 .51 & 15 \\
& 14.8 .53 & 16 \\
2 & 10.8 .56 & 3 \\
& 26.3 .52 & 9 \\
3 & 16.8 .56 & 14 \\
& 20.8 .51 & 14 \\
& 13.553 & 44 \\
4 & 23.555 & 10 \\
& 1.10 .56 & 4 \\
& 5.6 .55 & 6 \\
5 & 11.59 & 14 \\
& 7.10 .56 & 8 \\
& 7.1 .52 & 28 \\
6 & 8.12 .53 & 22 \\
& 13.7 .56 & 12 \\
7 & 3.7 .55 & 56 \\
& 31.7 .56 & 14 \\
8 & 15.3 .40 & 28 \\
8 & 26.2 .51 & 19 \\
& 3.12 .55 & 17 \\
& 2.4 .51 & 50 \\
& 2.3 .53 & 15 \\
\hline
\end{tabular}

*The last attack in each case is that treated by reserpine. 


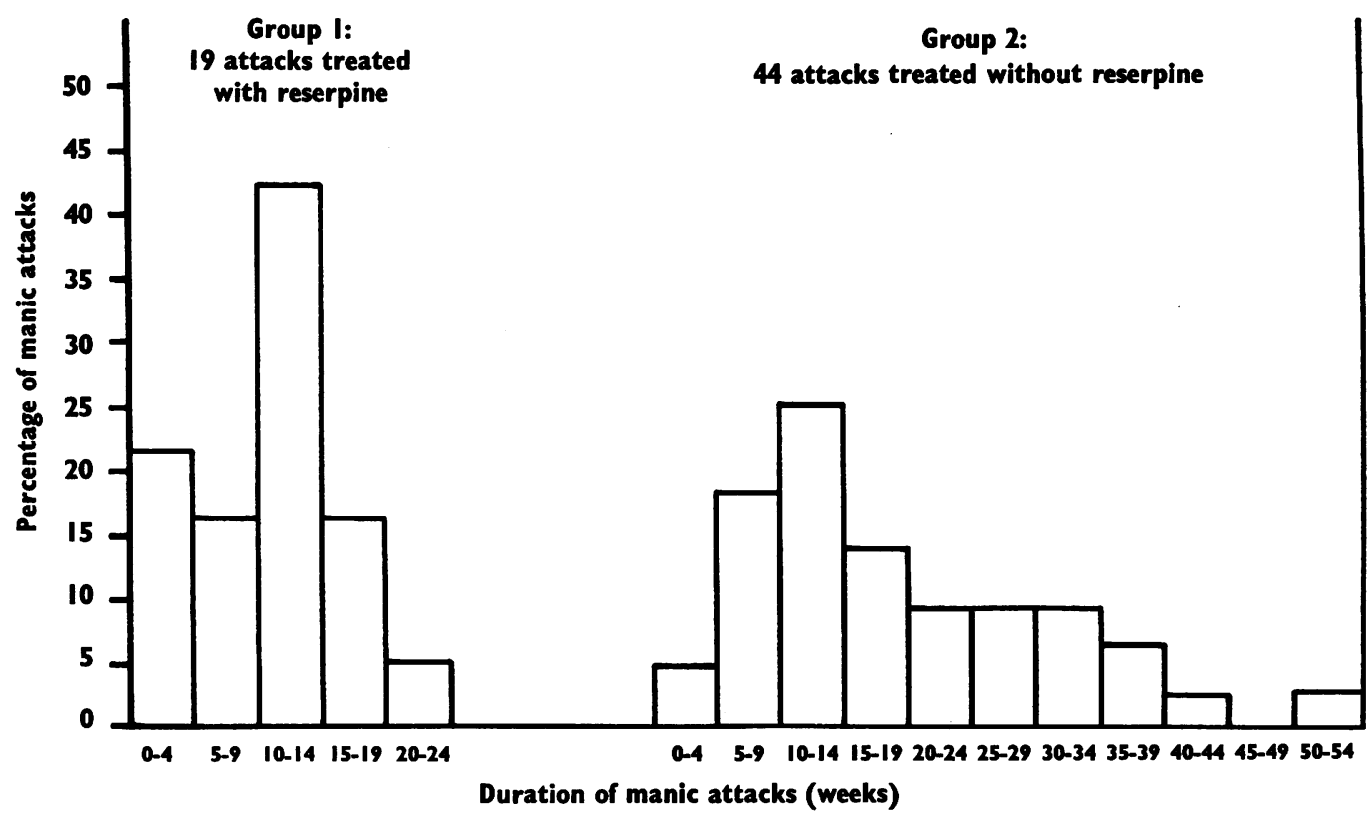

FIG. 1.-Frequency distribution of duration of hospital stay of manic attacks.

patients, the duration of the manic attack treated with reserpine and the duration of those attacks treated by other methods. Sixteen comparisons are possible, in individual patients, between manic attacks treated with reserpine and those treated otherwise, and in 13 the attack treated with reserpine is the shorter, the average difference being $13 \cdot 1$ weeks (taking sign into account). The numbers here are too small for statistical treatment, but the differences are in the same direction as those shown previously.

\section{Discussion}

The results demonstrate that reserpine shortens the duration of manic attacks. The histograms in Fig. 1 show the frequency distribution of the durations of attacks of mania expressed as a percentage for each group of attacks. It can be seen that in the group treated with reserpine the proportion of excessively long attacks is less and of short attacks more than in the group in which reserpine was not used.

It would have been ideal but impracticable to have the reserpine-treated group and the control group contemporary because of the infrequent occurrence of manic attacks. It may be objected that the two groups are not comparable because policy with regard to discharge may have altered during the period (1951-57) in which the subjects of this investigation left the hospital. The difference between the two groups cannot be accounted for by more hasty discharge of the patients in Group 1, however, as the mean duration of the period between recovery and discharge is the same for both groups. It must be admitted that the date of recovery might be more promptly noted in the reserpine-treated group who were under surveillance by the author because of their novel treatment. Little weight can be placed on the figures for the duration of the period between the onset of the attack and admission to hospital, but, such as they are, the disparity between them could not account for the difference in average duration of hospital stay between the two groups. In any case, it is conjectural what effect the length of the period between the onset of the attack and admission to hospital has on the duration of the period between admission and recovery. More general changes in hospital administration and function may possibly influence the rate of recovery. If, however, Group 2 is divided into periods 1951-52 and 1953-55, each containing 22 attacks, the average duration of stay in hospital during the early period (1951-52) is 18.9 weeks and during the later period $(1953-55)$ is $19 \cdot 2$ weeks.

The comparatively lesser duration of hospital stay in the majority of the attacks treated with reserpine, in those patients with recurrent attacks, supports the evidence already presented that the effect of reserpine is to shorten manic attacks.

Table II shows the duration of stay in hospital of 
TABLE II

DURATION OF HOSPITAL STAY IN MANIC ATTACKS AS PUBLISHED BY SEVERAL AUTHORS

\begin{tabular}{|c|c|c|c|}
\hline \multirow{2}{*}{ Author } & \multicolumn{2}{|c|}{$\begin{array}{l}\text { Average Duration } \\
\text { of Hospital Stay } \\
\text { (weeks) }\end{array}$} & \multirow{2}{*}{ No. of Cases } \\
\hline & $\begin{array}{c}\text { No Specified } \\
\text { Treatment }\end{array}$ & $\begin{array}{c}\text { Specific } \\
\text { Treatment }\end{array}$ & \\
\hline $\begin{array}{l}\text { Rennie (1942) } \\
\text { Tómasson (1936) }\end{array}$ & $\begin{array}{l}20 \cdot 6 \\
25 \cdot 7\end{array}$ & $\overline{\overline{1}}$ & $\begin{array}{l}42 \\
24\end{array}$ \\
\hline $\begin{array}{l}\text { Panse"(1924) } \\
\text { Lundquist (1945) } \\
\text { Wertham (1929) } \\
\text { Malzberg (1929) } \\
\text { Oltman and Friedman } \\
\quad \text { (1950) }\end{array}$ & $\begin{array}{l}2 \overline{27 \cdot 3} \\
31 \cdot 3 \\
34 \cdot 6 \\
35 \cdot 3 \\
42 \cdot 0\end{array}$ & $\begin{array}{l}15 \cdot 4 \\
= \\
=\end{array}$ & $\begin{array}{r}1 \overline{21} \\
2,000 \\
2,000 \\
318\end{array}$ \\
\hline $\begin{array}{l}\text { Morrow and King (1949) } \\
\text { Present author } \\
\quad,\end{array}$ & $\frac{7}{19 \cdot 0}$ & $\begin{array}{c}18 \cdot 2^{*} \\
8 \cdot 4^{\dagger} \\
11 \cdot 0\end{array}$ & $\begin{array}{l}58 \\
46 \\
44 \\
19\end{array}$ \\
\hline
\end{tabular}

* Measured from start of treatment.

tIncludes only those patients who recovered during period of treatment.

patients with manic attacks taken or derived from figures published by several authors. These data were collected under varying conditions and no strict comparison is possible. The lower average figures in the small groups of attacks are possibly accounted for by more careful selection of cases and more stringent diagnostic criteria. It can be seen that only two authors compare the duration of attacks in treated and untreated groups. Tómasson (1936) gives a careful account of the duration of manic attacks in 21 cases treated with ephedrine and acetylcholine. The average duration of hospital stay for these patients was 15.4 weeks which compares favourably with other patients not treated by his method. There are, unfortunately, no other published accounts of this treatment, although Tómasson still uses it (personal communication, 1957). Oltman and Friedman (1950) give the frequency distribution of the duration of the period between the start of E.C.T. and discharge from hospital in 58 cases, which gives an average of $18 \cdot 2$ weeks. The average for cases not treated with E.C.T. is 42.0 weeks, but it should be noted that this figure refers to the total duration of hospital stay. Morrow and King (1949) give an average stay in hospital of 8.4 weeks for 46 patients suffering manic attacks. This figure, however, includes only those patients where recovery took place during the period of treatment and not those in whom it did not. Moreover, these patients were in a private clinic, and it cannot be doubted that the expense to the patient would influence the therapist in favour of early discharge.

\section{Summary}

A clinical trial is described in which the average duration of hospital stay in 19 manic attacks treated with reserpine is compared with that in 44 manic attacks not treated with this drug and is found to be significantly smaller.

The two groups were not contemporary, but it is shown that it is improbable that this difference between them could be accounted for by shorter hospital stay following recovery in the group treated with reserpine or by other changes in hospital policy.

In eight patients who had had several attacks of mania the attack treated with reserpine was, in the majority of instances, shorter than the patients' other attacks.

I wish to thank Dr. S. L. Last by whose permission this investigation was carried out and Mr. T. G. Crookes who advised on the statistical treatment of the results.

\section{REFERENCES}

Altschule, M. D. (1956). New Engl. J. Med., 54, 515.

Barsa, J. A., and Kline, N. S. (1955). A.M.A. Arch. Neurol. Psychiat., $74,280$.

Brooks, G. W. (1956). New Engl. J. Med., 254, 1119.

Cade, J. F. J. (1949). Med. J. Aust., 2, 349.

Colombati, S., and Benassi, P. (1954). Gazz. med. tral., 113, 301.

Deron, H. C.' R. (1928). Le Syndrome Maniaque. Doin, Paris.

Flach, F. F. (1955). Ann. N.Y. Acad. Sci., 61, 161.

Glesinger, B. (1954). Med. J. Aust., 1, 277.

Glynn, J. D. (1955). J. Neurol. Neurosurg. Psychiat., 18, 225.

Hennelly, T. J. (1936). J. ment. Sci., 82, 608

Hes, J. Ph., and Bracha, S. (1956). libid., 102, 546.

Kearney, J., and Courtney, P. J.' (1938). Ibid., 84, 177.

Kirkpatrick, W. L., and Sanders, F. (1955). Ann. N.Y. Acad. Sci., 61, 123.

Kinross-Wright, V. (1955). Ibid., 61, 174

Lewis, A. (1956). In Price's Textbook of the Practice of Medicine. Oxford University Press.

Lundquist, G. (1945) Acta psychiat. (Kbh.). Suppl. 35.
Luttrell, R. R., and Morrison, A. V. (1955). Ann. N.Y. Acad. Sci., 61,183 .

Malzberg, B. (1929). Psychiat. Quart., 3, 590.

Mayer-Gross, W., Slater, E., and Roth, M. (1954). Clinical Psychiatry Cassel, London.

Morrow, J. K., and King, J. P. (1949). Amer. J. Psychiat., 105, 816. Noyes, A. P. (1953). Modern Clinical Psychiatry, 4th ed. Saunders, Philadelphia.

Oltman, J. E., and Friedman, S. (1950). Amer. J. Psychiat., 107, 57.

Panse, F. (1924). Mschr. Psychiat. Neurol., 56, 41.

Rennie, T. A. C. (1942). Amer.J. Psychiat., 98, 801.

Rice, D. (1956). J. ment. Sci., 102, 604.

Sargent, W., and Slater, E. (1948). An Introduction to Physical Methods of Treatment in Psychiatry, 2nd ed. Livingstone, Edinburgh.

Sarwer-Foner, G. J., and Ogle, W. (1956). Canad. psychiat. Ass. J.,

Schiele, B. C., and Schneider, R. A. (1949). Dis. nerv. Syst., 10, 291.

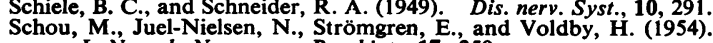
$J$. Neurol. Neurosurg. Psychiat., 17, 250.

Smith, L. H., Hastings, D. W., and Hughes, J. (1943). Amer. J. Psychiat., 100, 351 .

Sommerness, M. D., Lucero, R. J., Hamlon, J S., Erickson, J. L., and Matthews, R. (1955). A.M.A. Arch. Neurol. Psychiat., 74, 316 .

Tómasson, H. (1936). J. ment. Sci., $82,595$.

Vaughan, G. F., Lieberman, D. M., and Cook, L. C. (1955). Lancet, 1,1083 .

Wertham, F. I. (1929). Amer. J. Psychiat., 86, 17.

Wilson, R. S., and Gillman, S. W. (1938). J. ment. Sci., 84, 991.

Zeller, W. W., Graffagnino, P. N., Cullen, C. F., and Rietman, H. J. (1956)., J. Amer. med. Ass., 160, 179.

Ziskind, E., Somerfeld-Ziskind, E., and Ziskind, L. (1945). Arch. Neurol. Psychiat., (Chicago), 53, 212. 